\title{
The Jurassic pleurotomarioidean gastropod Laevitomaria and its palaeobiogeographical history
}

Roberto Gatto, Stefano Monari, János Szabó, and Maria Alessandra Conti

Acta Palaeontologica Polonica 60 (1), 2015: 217-233 doi: http://dx.doi.org/10.4202/app.2013.0012

The genus Laevitomaria is reviewed and its palaeobiogeographical history is reconstructed based on the re-examination of its type species L. problematica, the study of material stored at the National Natural History Museum of Luxembourg, and an extensive review of the literature. The systematic study allows ascribing to Laevitomaria a number of Jurassic species from the western European region formerly included in other pleurotomariid genera. The following new combinations are proposed: Laevitomaria allionta, L. amyntas, L. angulba, $L$. asurai, L. daityai, L. fasciata, L. gyroplata, L. isarensis, L. joannis, L. repeliniana, L. stoddarti, $L$. subplatyspira, and L. zonata. The genus, which was once considered as endemic of the central part of the western Tethys, shows an evolutionary and palaeogeographical history considerably more complex than previously assumed. It first appeared in the Late Sinemurian in the northern belt of the central western Tethys involved in the Neotethyan rifting, where it experienced a first radiation followed by an abrupt decline of diversity in the Toarcian. Species diversity increased again during Toarcian-Aalenian times in the southernmost part of western European shelf and a major radiation occurred during the Middle Aalenian to Early Bajocian in the northern Paris Basin and southern England. After a latest Bajocian collapse of diversity, Laevitomaria disappeared from both the central part of western Tethys and the European shelf. In the Bathonian, the genus appeared in the south-eastern margin of the Tethys where it lasted until the Oxfordian.

Key words: Gastropoda, Pleurotomariidae, systematics, palaeobiogeography, Jurassic, western Tethys.

Roberto Gatto [roberto.gatto@unipd.it] and Stefano Monari [stefano.monari@unipd.it ], Department of Geosciences, University of Padua, via G. Gradenigo 6, 35131 Padua, Italy; János Szabó [jszabo@nhmus.hu], Department of Palaeontology and Geology, Hungarian Natural History Museum, Ludovika tér 2, 1431

Budapest, Hungary; Maria Alessandra Conti [sandra.conti@uniroma1.it], Department of Earth Sciences, University of Rome "La Sapienza", P.le Aldo Moro 5, 00185 Rome, Italy. 
This is an open-access article distributed under the terms of the Creative Commons Attribution License (for details please see creativecommons.org), which permits unrestricted use, distribution, and reproduction in any medium, provided the original author and source are credited.

For Full text $(1,328.8 \mathrm{kB})$ 